\title{
Perception and Preference towards Online Education in Nepali Academic Setting Manish Thapa ${ }^{1}$ \\ ${ }^{1}$ M. Phil Scholar, Kathmandu University
}

\begin{abstract}
Education setting evolved from historical open learning system to traditional classroom set-up to distance learning modality. Teaching-Learning practice is transformed with an evolution of teaching-learning materials. With technological advancement in progressive manner and it's increasing use in academic setting, distance learning has been the on-demand and on-debate topic in current educational discourse. Comparatively fresh topic in Nepali academic setting, this paper intended to analyze the perception of Nepali students towards online modality in Nepali academic setting. This paper further analyzed the student's preference towards distance learning in current Nepali academic setting. Research findings were analyzed based on data collected through literature review, interview with students and professor and quantitative data collection through use of google form.
\end{abstract}

Study identified opportunities as revenue generation; continuation of academic career from any part of country; increase learning outcome among jobholders. Study identified challenges as unequal access and quality of internet facilities; affordability of laptops/computers; limited interaction; and frequent disturbances. Seeing the better prospects, study strongly supported the need of shift in academic shift from traditional setting to non-traditional setting in Nepali context to meet the global needs of competitive and quality education.

Keywords: Distance, Learning, Academic, Education, Students, Teaching-Learning, Modality

\section{Introduction}

The classroom has always reflected a society's views about goals of education. Talking about teaching modality, usually we think of classroom structure with placement of desk benches inside the four wall or concrete structures. It was not always the same. Before the concrete-classroom set-up, there were other kind of teaching methodologies such as teaching in natural environment i.e. open ground, under the big tree, etc. With time and evolution of structures, the teaching practices and classroom set-up has also evolved. And the traditional classroom set-up has slowly and gradually replaced by distance learning i.e. non-traditional mode of delivery systems. System where teaching and learning system are performed through use of communication technologies sitting in different environment are termed as distance learning (Tavukcu. et. al, 2011). UNESCO (2002) characterized distance education by its focus on open access to education and training provisions, freeing learners from the constraints of time and place, and offering flexible learning opportunities to individuals and group of learners.

Looking back to the history, technology has always been at the lead of education setting. Since 2000s, evolution of technology happened in very quick manner. In academic setting, chalkboards were replaced by whiteboards and smartboards. Notebooks and textbooks were replaced by laptops and tablets. More importantly, different type of teaching-learning materials were widely adopted in the form of online forums, use of social networking sites, audio, visuals, and presentations slides. By 2020, 1000s of academic institutions across the world has been conducting full fledge certified degrees from distance learning modality. Likewise, there are millions of people, who study through videos from youtube, short term (credited/non-credited and certified/non-certified) course at different online course platforms such as coursera, edx, etc. Each passing day, number of students searching for distance mode of learning to pursue higher degree (academic) is in increasing number.

In current age, technologies have been widely used to deliver course content. Print materials, broadcasting through television and radios, video conferencing through apps such as skype, zoom, viber, google meet, etc., sharing of educational materials through e-mail and discussion through online based forums has been 
widely adopted to have interaction sessions. The use of appropriate technologies and their efficiency is appearing to be very crucial to have an effective distance learning or distance learning. Once widely acknowledged "face-face" set-up has slowly been shifted towards "virtual" set-up. In developed countries, with well-facilitated technology set-up, distance learning or distance learning has been officially recognized and widely adopted.

In case of Nepal, whenever we think of education setting or classroom setting, we think of interactions between instructor-student and student-student, use of coursebook, group exercises, classroom exercises, use of chalkboard/whiteboard, duster, etc. inside the closed space. In case of distance learning, everything remained technology based. Looking at the underlying socio-economic scenario of children and accessibility of advanced technologies at rural level, adoption of distance learning modality remains the topic to be widely researched and discussed in Nepali academic setting.

Regards to adoption of distance mode of learning, year 2020 played the role of catalyst for nationwide discussions among policymakers and stakeholders as institutional schools were forced to imply distance learning modality for almost one full session. Even government schools initiated adopting them at school level. Meanwhile, private institutions with academic level at bachelors or above continuously adopted distance mode to continue classes and oversee exams. As the academic institutions already initiated distance teaching-learning modality, this research tends to explore the perception of students and their preference for forthcoming days.

\section{Rationale for the Study}

Distance Learning has relatively succinct history in comparison to traditional teaching-learning approach i.e., classroom setting. At personal level, researcher have taken 30+ credited/non-credited short courses through different distance course portal sites. COVID-19 pandemic situation gave an opportunity to attend credited academic courses during M. Phil degree. It brought curiosity to explore more on the distance learning and its applicability in academic courses at national level.

COVID-19 pandemic forced Kathmandu University and Tribhuwan University to adopt distance learning modality to continue curriculum at varied level. Likewise, institutional schools adopted distance teaching learning modality to continue academic session at all grade (from grade 1 to grade 10). It has been widely perceived that, with the number of research work on student's experience and perception towards any subject or issue, there lies the potentiality to design and introduce the programs more appropriately. Such programs tend to be highly acknowledged by students at long term.

\section{Objectives of Research}

The aim of the research is to explore the prospects of adoption of Distance Learning (DL) at academic institutions based on the current socio-economic, education and technological settings. This study broadly has two objectives:

i. To explore the perception of student towards distance learning

ii. To explore the preferred mode of teaching-learning modality

\section{Research Question}

The study questions for the study is as following:

a. How do students perceive about the adoption of Distance Learning in Nepali academic setting?

b. Which mode of learning is preferred among Nepali students?

\section{Limitations of the Study}

Questionnaire was sent to random students through virtual mode. Based on their interest, student was provided with opportunity to share the questionnaire to their friends and colleagues. The findings 
obtained from the smaller sample size for the survey may not be generalizable to overall context of education setting.

As the questionnaire was sent through mail as well in group mail approach, it may have been automatically been flagged into junk email or spam email, thus potential participants never getting an opportunity to look at the questionnaire.

\section{Literature Review}

In education setting, the use of technologies and distance learning has its own share of history. Distance Learning was first adopted in 1728 with the use of newspapers. In 1833, Swedish University started composition courses with letter, which was provided to women. Pant (2014) briefly discussed about the history of distance education in global setting in his article. In case of UK, Pitman delivered shorthand instruction using correspondence in 1840. State of New York authorized academic degrees in 1883-1891, that were delivered through correspondence. Illinois Wesleyan started full fledge bachelors, masters and doctoral degrees from 1890s. Moody Institute, which was founded in 1886 has taught over 1 million students across the world since 1901 through distance learning modality. In Sweden, world's leading institution namely Hermands was founded in 1898. Hermand introduced language education.

Technology wise, Magic Lantern were used as a slide projector back in 1870 (Purdue University) ${ }^{1}$. Magic Lantern projected images printed on glass plates. Chalkboard were globalized in late 1800s. Whereas, pencil was introduced in 1900. Repeatedly, different form of advanced educational tools was introduced and used worldwide. From 1920s, on-air classes were introduced through use of radio from USA. Wisconsin's School of Air was among the early adopter of distance learning to delivery academic courses. Academic courses were broadcasted through television for the first time by IOWA university in 1932. From 1930-1950, different tools were introduced such as overhead projector (1930), ballpoint pen (1940) and headphones (1950) (Purdue Online). 1960 was one of the benchmark years for distance learning as British Open University was founded in England (McIsaac. S. M. \& Gunawardena. N. C, 2001). It began the use of technology to supplement print-based instruction through well-designed courses. Whereas University of Wisconsin in 1986 started using technologies for effective distance education. During these periods and after, audio and computer teleconferencing has influenced education sector in terms of delivery of courses in academic institutions at all level. Based on the learning from Britain and USA, Asian countries such as Pakistan, China and India started adopting technologies for delivering academic courses around 1990s. By 1993, academic institutions of Turkey adopted distance learning modality to deliver courses to millions of students.

Nepali education setting has been dominated by face-face teaching-learning system. Historically, it was limited to education setting at Gurukul (teacher's home or temple), Gumba (ran by Buddhist community) and Madrasa (ran by Muslim community) (Pangeni, 2016). At the same time, formal education was started after establishment of Durbar School in 1853 (Sapkota, 2012). 1958 was the benchmark year for Nepal for Distance Learning as adult education program was broadcasted through radio by College of Education. In 1971, New Education System Plan (NESP) was implemented enforcing mandatory environment for teachers to receive training to have permanent tenure. During 1978, Ministry of Education launched radio education teacher training program. Officially, Distance Education Centre (DEC) was established in 1994 which was initially provisioned by National Education Commission (1993). It has been broadcasting teacher training and education awareness program through radio.

Policy wise, $10^{\text {th }}$ Five Year National Development Plan (2002-2007) has been the benchmark year from the perspective of policy formulation and inclusion of potential distance learning in education sector. Plan highlighted the need of open university to broaden accessibility to higher education. Government of Nepal formulated Open Education and Distance Learning (OEDL) Policy 2007. OEDL Policy helped 
formalizing distance learning programs and setting up education institutions focusing on distance learning. Establishment of Open University was further stressed out by Three-year Interim Plan (20072010). Open and Distance Education Center (ODEC), International Center for Academics, College of Professional Studies, British Council Nepal, College of Distance Education and Online Studies (CDEOS) and National Open University (NOU) has been supplying full-fledge academic course for last couple of decades. Whereas Kathmandu University (KU) has been offering blended courses to students across the globe.

With the evolution of technologies i.e. 1980s, distance education has seen dramatic growth at international level. Education set-up has evolved from traditional set-up to non-traditional set-up and paper-based teaching to technology-based teaching. With the evolution of internet technologies and social networking sites since 2000 s, instructors started creating groups and forums at online platform for sharing educational materials and discussing on academic courses and topics. In current scenario, there are distance education courses offered by 1000s of public and private academic institutions across the world. 1000s of academic courses are being delivered through use of radio, TV, online platform.

During the COVID-19 pandemic situation, the potentiality of distance learning in Nepali Academic institution has been among the widely discussed topic in Nepali context. Pandemic forced academic institution to close their curriculum at every level. Government of Nepal continued delivering SEE related tuition through radio/TV broadcasting across the country. Academic institutions such as Kings College, Ace College, Tribhuwan University (TU), Kathmandu University (KU), etc. adopted distance mode to deliver curriculum viz application of tools such as zoom, moodle, google meet, skype, slack, canvas, etc.

\section{Theoretical Perspective}

Talking about the objective of the research to explore the prospect of distance learning in academic institutions of Nepal, no single theory could be utilized to relate the context with learnings. Thus, study is revolved around the theories "Community of Inquiry (CoI)" and "Theory of Transactional Distance". Community of Inquiry (CoI) provide in-depth insight through intersection of social, teaching and cognitive presence. As argued by Garrison et. al. (2011), complete educational experience in distance collaborating learning setting get developed with the cognitive presence, social presence and teaching presence. It has further been backed up by Purdue (2018) with the statement, CoI is the social constructivist model of learning process in distance environments.

While explaining various aspects of distance learning, study on level of interaction between studentinstructor and student-student plays influential role. The lower level of interaction leads to communication gaps and provide space of potential misunderstandings between instructor and learners. As per Moore (1997), dialogue, structure and learner autonomy determine the nature of transaction between teachers and students during distance classes.

\section{Research Methodology}

Research adopted both quantitative and qualitative approaches to collect data incorporating review of literatures and scholarly works on distance learning, utilization of authors' own reflection after attending distance classes since the start of lockdown in Nepali context and quantitative survey through virtual form. The questionnaire was designed to cover different aspects of the distance learning such as a) accessibility of technologies and internet facilities, b) level of interaction between student-student and student-teacher and the participation of students for active learning, c) Continued learning opportunity without any distraction and d) application of e-learning mode for all type of courses. Multiple theories were considered while constructing the questionnaire such as theory of community of inquiry (CoI) and theory of transactional distance learning. 


\section{Data Collection}

Questionnaire was designed and uploaded in the google form. As the potentiality of carrying out the physical survey is quite not possible due to the COVID-19 pandemic and lockdown scenario, survey was carried out through virtual mode adopting google form.

Total of 160 students with or without the prior experience on distance learning at academic level. Research included student with as well as without prior experience on distance learning which made research rich with analysis from multi-dimensional scenario.

Table 1 Questions included in the survey

\begin{tabular}{|c|c|}
\hline Theme & Questions \\
\hline Social \& Academic & $\begin{array}{ll}\text { 1. } & \text { Gender } \\
\text { 2. } & \text { Age Group } \\
\text { 3. } & \text { Academic Level (Most Recently Completed or Ongoing) }\end{array}$ \\
\hline $\begin{array}{l}\text { Experience on } \\
\text { Distance Learning }\end{array}$ & $\begin{array}{l}\text { 1. Prior experience on distance learning } \\
\text { 2. Academic level of prior experience } \\
\text { 3. Country of prior experience } \\
\end{array}$ \\
\hline Technology Based & $\begin{array}{l}\text { 1. Electronic Instrument used during distance classes } \\
\text { 2. Preferred electronic instrument to attend distance classes } \\
\text { 3. Perception towards affordability of laptop/PC by students } \\
\text { 4. Perception towards comfort with available technology } \\
\text { 5. Perception towards comfort with available internet facilities }\end{array}$ \\
\hline $\begin{array}{l}\text { Level of Interaction, } \\
\text { Distraction, Clarity } \\
\text { on content }\end{array}$ & $\begin{array}{l}\text { 1. Perception of degree of interaction/discussion } \\
\text { 2. Perception towards clarity in information from instructor } \\
\text { 3. Perception towards attentiveness among students } \\
\text { 4. Perception towards probable distraction during class }\end{array}$ \\
\hline $\begin{array}{l}\text { Use of Teaching- } \\
\text { Learning Materials }\end{array}$ & $\begin{array}{l}\text { 1. Preferred Teaching-learning material } \\
\text { 2. Teaching-learning material used by instructor }\end{array}$ \\
\hline Applicability & $\begin{array}{l}\text { 1. Perception towards applicability of distance mode for theory } \\
\text { based courses } \\
\text { 2. Perception towards applicability of distance mode for technical } \\
\text { courses } \\
\text { 3. Perception towards applicability of distance mode for course } \\
\text { requiring group exercises, demonstrations and practical's } \\
\text { 4. Perception towards adoption of distance mode in Nepali academic } \\
\text { institutions (at any level) } \\
\text { 5. Perception towards adoption of distance mode in Nepali academic } \\
\text { institutions (Under SEE) } \\
\text { 6. Perception towards adoption of distance mode in Nepali academic } \\
\text { institutions (Plus 2) } \\
\text { 7. Perception towards adoption of distance mode in Nepali academic } \\
\text { institutions (Bachelor) } \\
\text { 8. Perception towards adoption of distance mode in Nepali academic } \\
\text { institutions (Masters and above) }\end{array}$ \\
\hline Preference & $\begin{array}{l}\text { 1. Experience of distance learning mode } \\
\text { 2. Preferred modality }\end{array}$ \\
\hline
\end{tabular}

Data Analysis

Data collected through virtual survey were first downloaded into excel, then analyzed with the help of quantitative survey analysis software i.e. SPSS. The responses were coded into the 5-Likert scale (Most 
Likely) to make the responses measurable and computable which corresponds descriptive values as in Table 2 (Pimentel, 2011).

Table 2: Description of Mean Rating

\begin{tabular}{lccr}
\hline Likert Scale & Interval & Difference & Description \\
\hline 1 & $1.00-1.79$ & 0.79 & None \\
2 & $1.80-2.59$ & 0.79 & Low \\
3 & $2.60-3.39$ & 0.79 & Moderate \\
4 & $3.40-4.19$ & 0.79 & High \\
5 & $4.20-5.00$ & 0.79 & Very High \\
\hline
\end{tabular}

Descriptive statistics in the form of mean and standard deviation is used to describe the data. Meanwhile, Mann-Whitney $\mathrm{U}$ test is used to compare the mean between group of data between student with experience and prior experience.

\section{Ethical Considerations}

To address the potential ethical concerns, none of the participants were compensated. As the context during study period was lockdown, study followed the norms and applied remote survey approach. It followed the lockdown rules and/or social distancing. Likewise, the name of participant and institution were kept anonymous and were not included in any portion of analysis, there lies no risk in publishing this study findings in public.

\section{Result and Finding Profile of the Respondents}

A total of 157 valid responses were recorded. Majority of the respondents were male $(74 \%, \mathrm{n}=116)$. The largest age group was between 20 and 30 years of age $(60 \%, \mathrm{n}=94)$ followed by 30-40 years of age $(23 \%, \mathrm{n}=37)$. Almost half $(49.04 \%, \mathrm{n}=77)$ were bachelor graduates followed up by masters/postgraduates $(40.13 \%, \mathrm{n}=63)$. Most importantly, over half $(56.69 \%, \mathrm{n}=89)$ of the participants had prior experience on distance learning. As the survey incorporated majority of responses from bachelor graduate, same group also led the group having prior experience with $49 \%(\mathrm{n}=44)$. The sociodemographic characteristics of the participants are summarized in Table 3.

Table 3 Socio-Demographic Profile of Participants

\begin{tabular}{lcr}
\hline Socio-Demographic Characteristics & Frequency & Percentage \\
\hline Gender & 41 & \\
Female & 116 & 26.1 \\
Male & & 73.9 \\
Age Group & 20 & 12.7 \\
Less than 20 years & 94 & 59.9 \\
21-30 years & 37 & 23.6 \\
31-40 years & 6 & 3.8 \\
40 years and above & 2 & \\
Academic Level & 4 & 1.3 \\
SEE & 77 & 2.5 \\
Plus 2 & 63 & 49 \\
Bachelor & 11 & 40.1 \\
Post Graduate/ Masters & & 7 \\
M. Phil./Ph.D. & & \\
Prior Experience on Distance Learning & &
\end{tabular}




\begin{tabular}{lcr}
\hline Socio-Demographic Characteristics & Frequency & Percentage \\
\hline Without Experience & 68 & 43.3 \\
& 89 & 56.7 \\
Academic Level (Among Prior & & \\
Experience) & 1 & 0.6 \\
SEE & 7 & 4.5 \\
Plus 2 & 33 & 28 \\
Bachelor & 44 & 21 \\
Post Graduate/Masters & & \\
Country with Prior Experience & 62 & 80.5 \\
Nepal & 15 & 19.5 \\
Outside Nepal & & \\
\end{tabular}

\section{Technology Based}

In practical scenario, diverse type of instrument was found to have used by students to participate on distance classes. The type of device plays significant role as it is also linked with comfort to use and see the display shared by instructor. Meanwhile, it is also linked with affordability, whether student can afford preferred device by students and instructors.

Table 4 present an information about the most frequently used devices to attend the distance classes. It also gave idea on which devices are mostly preferred by students to attend class whenever they get the chance to do so. Among the devices which were used by participant to attend the class, laptop $(86.5 \%, \mathrm{n}=$ 77) was the mostly used one followed up by smartphone $(42.7 \%, \mathrm{n}=38)$. Preference wise as well, majority $(87.9 \%, \mathrm{n}=138)$ preferred laptop to attend distance classes in forthcoming period. Table 4 Different type of instruments either used or preferred to attend distance classes

\begin{tabular}{lllcc}
\hline Alternatives & \multicolumn{2}{c}{$\begin{array}{c}\text { Used by Participant during } \\
\text { Distance Class }\end{array}$} & $\begin{array}{c}\text { Preferred device to attend distance } \\
\text { learning (if they had to) }\end{array}$ \\
\cline { 2 - 5 } & Freq. & \% & Freq. & \% \\
\hline Laptop & 77 & 86.5 & 138 & 87.9 \\
Desktop & 7 & 7.9 & 18 & 11.5 \\
Smartphone & 38 & 42.7 & 48 & 30.6 \\
Tablet & 7 & 7.9 & 16 & 10.2 \\
Others & 1 & 1.1 & NA & NA \\
\hline
\end{tabular}

Though laptop was preferred by students to attend distance class, their availability and affordability among students from Nepal is another concern to dealt with. Kharel (2018) found, only $12.1 \%$ access computer facilities. There are 1000s of student (studying at bachelor or above) who do not have laptop and are still dependent on either friend's computer or cyber for computer-based assignments. As an alternative, talking class through mobile may serve the purpose.

As distance learning is all about learning through use of technology in online mode, perception from students about availability of internet facility, affordability of laptop and comfortability with available technology were important to explore. More than half (54.1\%) were not confident about affording laptop to pursue distance learning. From familiarity to available technology perspective, almost two fifth (38.9\%) participant showed their comfort on using currently available tools and technologies. Over $60 \%$ of the participants were not confident about having smooth internet facilities to attend distance classes. 
From descriptive statistics perspective, research participant perceived about the low ability among student to afford laptop to attend classes. Meanwhile, their familiarity with available technologies is moderate. Similarly, their satisfaction towards existing internet facilities is low. Based on Mann Whitney U Test, calculated p-value of $0.190,0.677$ and 0.467 is greater than 0.0 .5 ( $p$-value $>0.05$ ), it signifies the response between student with or without prior experience on distance learning tend to perceive the same regarding affordability of laptop ( $p$-value $=0.190)$, comfort with available technology $(p$-value $=0.677$ ) and satisfaction with internet facilities ( $\mathrm{p}$-value $=0.467$ ).

Table 5 Participants perception towards online learning from technology perspective

\begin{tabular}{lccr}
\hline Questions & Mean & Interpretation & Sig. (p-value) \\
\hline Affordability of Laptop & 2.37 & Low & 0.190 \\
Comfort with available technology & 3.22 & Moderate & 0.677 \\
Satisfaction with internet facilities & 2.28 & Low & 0.467 \\
\hline
\end{tabular}

In Nepali context, people take internet service either from internet service providers or buy internet packages from ntc/ncell. There are just over 1 million internet users through wireless, cable and fiber in Nepali context (NTA, 2020). $71.76 \%$ has access to internet services. Of which, $54.90 \%$ are from mobile broadband. In current scenario, there are multiple issues associated with internet facilities i) it has not reached to every part of country, ii) internet cost is high in comparison to other countries and iii) internet speed keeps on fluctuating. Because of these issues, consumers are not satisfied with available internet facilities. In such case, it would be difficult to imagine conducting distance classes. The survey findings complement overall scenario of Nepal in current setting.

\section{Level of Interaction, Distraction and Clarity}

Classes becomes effective if there will be more interaction and discussion. During the classes through distance mode, it significantly limits the interaction between students. Without much interaction, teaching-learning mode becomes monotonous. As per perception study, 34.83\% participant with prior experience on distance learning shared of being interaction at low to very low. Likewise, $38.24 \%$ of the participant (without prior experience on distance learning) perceived of distance classes being interactive at low to very low level.

With frequent internet disturbances, issues associated with microphone and echo, disruption from children at students' home, there lies the potentiality of getting disturbances during classroom period. $52.87 \%$ of participant perceived the distance classes being disturbed at high to very high level. With varied level of disturbances, there lies the potentiality of losing focus and not being clear on lectures and opinions shared by instructors and fellow students. $43.31 \%$ of the participant shared about potentiality to lose attention during distance class in any period of time. $25.48 \%$ perceived the instructors being unable to detail out the course content and clear all the queries of student through distance mode. Research participants shared about the moderate level of interaction or discussion to happen through online class, clarity in information and courses and attentiveness among students. Meanwhile, there lies the higher degree of distraction during classes.

In traditional classes, instructor can closely observe student's behavioral aspect and can understand whether the courses are being understood and acknowledged by student or not. Based on observation, lecturer tend to change their teaching modality instantly. But in case of distance learning, the aspect of close observation of student's behavior is of distant possibility. This creates uncomfortable scenario for instructor who tends to teach being interactive and engaging students.

P-value for all component is greater than 0.05 which signifies the perception between student of both types (with prior experience and without prior experience) doesn't have significant difference variance between their responses. 
Table 6 Participants perception towards level of Interaction, Distraction and Clarity

\begin{tabular}{lccr}
\hline Questions & Mean & Interpretation & Sig. (p-value) \\
\hline Interaction or Discussion in online mode & 2.74 & Moderate & 0.461 \\
Clarity in Information and courses & 3.10 & Moderate & 0.242 \\
Degree of attention among students & 2.66 & Moderate & 0.294 \\
Degree of distraction during class & 3.5 & High & 0.109 \\
\hline
\end{tabular}

\section{Use of Teaching Learning Materials}

Instructor tends to adopt diverse teaching modes during distance class than the traditional class-room setup. Usually, in classroom structure, teachers either use powerpoint or full lecture or through flyers. But in case of distance mode, teachers tend to have diverse options at their helm. $87.31 \%$ of the participant with prior experience on distance learning found teachers applying more than one mode. Likewise, $44.49 \%$ found teachers applying four or more modes. 85\% shared instructor using presentation slides, while $71 \%$ shared instructor using video clips to clarify the course content. In case of both scenario, use of presentation slides were either mostly used or mostly preferred approach of teaching-learning. However, the case for narration/ explanation only approach which is most preferred in traditional learning is the least preferred approach (34.4\%) among participants in forthcoming period which itself was the second most $(42.8 \%)$ adopted approach till date. Over two third (67.5\%) of the participants prefers video clips as teaching-learning materials if they have to attend distance class in future.

Table 7 Different type of teaching learning materials used (could be used) during distance classes

\begin{tabular}{llccc}
\hline Alternatives & $\begin{array}{c}\text { Was in Use during distance } \\
\text { class (actual scenario) }\end{array}$ & $\begin{array}{c}\text { Could be used during distance class } \\
\text { (perception) }\end{array}$ \\
\cline { 2 - 5 } & Freq. & \% & Freq. & \% \\
\hline Video Clips & 26 & 33.7 & 106 & 67.5 \\
Presentation Slides & 60 & 77.9 & 137 & 87.3 \\
Audio Clips & 12 & 15.5 & 65 & 41.4 \\
Narration/ Explanation only & 33 & 42.8 & 54 & 34.4 \\
Others & 7 & 9 & 24 & 15.3 \\
\hline
\end{tabular}

\section{Preferred Level and Course Modality}

All courses are not of same time. Some courses require group exercises, practical's and demonstrations whereas some courses only require student's engagement through speech or presentation form. Courses such as statistics requires complete exercise type teaching-learning modality while for courses like literature, only interaction or one-way communication can help as well. But in case of distance course, there lies the possibility of only interaction or complete instruction-based teaching-learning practices. The scenario makes distance mode difficult to be applied for all type of academic courses.

Based on the type of course, $57.3 \%$ responded the distance mode being suitable for delivering theorybased courses. Whereas $49 \%$ responded the distance mode being not suitable enough for technical courses. Likewise, $70.51 \%$ straightforwardly rejected the idea of distance learning being applicable for courses requiring group exercises, demonstrations and practical.

From meaning making perspective, participant perceived the applicability of distance learning for theory based course is high. As the p-value (0.844) is greater than 0.05 , the responses are not statistically different across the type of responses. However in case of the technical course, the p-value being 0.279 and mean value being 2.59 , almost all responses consistently shared about distance learning being applicable at lower rate and consistent responses across the students, regardless of their type. In case of 
distance learning being applicable to practical course, p-value (0.035) is greater than 0.05 thus is statistically different. Meaning, though the mean value is found to be low, there lies the probability of different responses across the responses from different group of students.

Due to the nature of distance learning, $69.4 \%$ preferred the distance classes not to be introduced for classes under SEE. $47.1 \%$ recommended the course not to be introduced at plus 2 level. $48 \%$ felt, this could be introduced at bachelor level. Whereas $70 \%$ felt this can be introduced at masters or above. From meaning making perspective, participant perceived the applicability of distance learning being moderate at all level with p-value being 0.215 greater than 0.05 and is statistically not different across groups. In case of applicability of distance mode for under SEE, perception rate is at lower level and statistically not different ( $p$-value of $0.111>0.05$ ). In case of applicability of distance mode for high school, participant perceived it as moderate level with statistically not different finding (p-value of 0.146>005). However in case of bachelor and master and above, though in both cases, perception rate lies at higher level, their pvalue of 0.014 and 0.036 is lesser than 0.05 . Meaning, there lies the finding being statistically significant or different between groups.

Table 8 Participants perception towards applicability based on course modality

\begin{tabular}{lccr}
\hline Applicability on & Mean & Meaning & Sig. (p-value) \\
\hline Type of Course & & & \\
\hline Theory based course & 3.52 & High & 0.844 \\
Technical Course & 2.59 & Low & 0.279 \\
Practical Course & 2.22 & Low & 0.035 \\
\hline Academic Level & & & 0.215 \\
At all level & 2.87 & Moderate & 0.111 \\
Under SEE & 2.04 & Low & 0.146 \\
High School & 2.68 & Moderate & 0.014 \\
Bachelor & 3.41 & High & 0.036 \\
Master and above & 3.90 & High & \\
\hline
\end{tabular}

\section{Preferred Modality}

Among research participants, majority (85.4\%) shared about the blended course as the preferred modality while traditional classroom set-up only as the least preferred one. Meanwhile, student without prior experience also preferred blended course (89.7\%) with an application of both online/virtual mode and traditional classroom mode.

Table 9 Preferred Modality among Research Participants

\begin{tabular}{lcccc}
\hline Preferred Modality & $\begin{array}{c}\text { Among student with prior } \\
\text { experience }\end{array}$ & $\begin{array}{c}\text { Among student without } \\
\text { prior experience }\end{array}$ \\
\cline { 2 - 5 } & Freq. & $\%$ & Freq. & \% \\
\hline Blended Course & 76 & $85.4 \%$ & 61 & $89.7 \%$ \\
Online Only & 7 & $7.9 \%$ & 1 & $1.5 \%$ \\
Traditional Classroom set-up only & 6 & $6.7 \%$ & 6 & $8.8 \%$ \\
\hline
\end{tabular}




\section{Additional attributes of Distance Learning Enrollment from anywhere}

Either it be at +2 , Bachelor, Masters or above, student need to come to Kathmandu for quality education. Student from middle class or higher class can afford to study in Kathmandu. But that is not the same for all students. It creates disparity among student to afford quality college and universities. Furthermore, in case of student who need to enroll in professional activities need to wait for years to land Kathmandu based job and pursue academic career. If there are the opportunities of distance or distance learning, there lies the potentiality among student to enroll in chosen course from any part of the country. It reduces economic burden over them and their family. Furthermore, student engaging at professional activities can manage time and continue education and job at the same time. It helps student to remain competitive, educated and more concentrated from continuous education.

\section{Source of Income Generation or Revenue}

There lies the high possibility of enrollment, if there is good promotion, proven and effective delivery of courses. Not only inside the country, but also, student from any part of the world can enroll. With an increased enrollment and increased no. of student, it is definite to increase income for institutions as well. In global scenario, education sector has become the one of the key revenues generating sector in developed countries such as UK, USA, and Australia. In 2016 and 2018 (Dodd, 2016), Australia generated $\$ 21$ billion and $\$ 32$ billion a year respectively from education exports. As per U.S. Department of Commerce, international students contributed $\$ 45$ billion to U.S. economy in 2018. Likewise, $£ 21.4$ billion was contributed by education exports in UK during 2017. In Nepali context, revenue through education sector has been very less. Kathmandu University (KU) and Tribhuvan University (TU) has been enrolling students outside of Nepal since long time. However, the number is incredibly low. If there lies the potentiality of attracting student from abroad, Nepal can generate revenue from academic institutions i.e. from enrollment of foreign students.

\section{Save Time, Energy}

The number of people engaging in job and academia at same time has significantly increased in last decade. As reported by Deruy (2015) in USA, 7 out of 10 students work while they are enrolled in academic course. Chantrea. et. al. (2018) mentioned 7 out of 10 students from university of Cambodia engaged at full time job. Though, there are not such study been conducted in case of Nepal, the number of students engaging at professional work is in increasing trend. Mostly, them being engaged at outsourcing activities. Among such students, time management becomes the issue to dealt with. Either job-class or class-job, their life becomes hectic and tedious. Because of requirement of travel in between, energy is drained, which affect learning ability as well. In such case, if there is an opportunity of distance classes, time required to travel from job-class or vice versa could be saved. As studies has proved, fatigue can affect learning ability, such situation could be managed with provision of distance learning.

\section{Increase Participation}

As we have seen quite often, not all students get easy to interact in classroom. There will always be some $30-40 \%$ of student who interact often while other remain silent inside classroom. Abdullah. et. al. (2012) found, due to language barrier and fear of being laughed by friends, student tend to remain silent and do not speak in front of instructor instead ask to their friends. 53\% of students fear of speaking in front of others in class (Abebe. T. D. \& Deneke. T. D., 2008). In distance mode, there is not mandatory for student to face another student like in classroom. Also, there is the provision of raising questions or interactions through chatting mode as well. Thus, distance learning modality becomes fruitful to increase participation of student who fear of speaking in-front of other students.

\section{Conclusion}

Distance Learning is innovative approach of learning modality in education system with less than 300 years of history in global context and less than 70 years in Nepali context. Like in developed countries, 
Nepal does have its own share of history behind adoption of distance learning. Though, it was not as part of academic curricula but still is relevant for development of education setting. With the introduction of technologies, the learning modality has been gradually shifting from traditional education setting to nontraditional academic setting.

Evolution of technologies presented the new dimension and opportunities in academic setting. However, with opportunities, there lies the challenges as well. Even having experience of more than two century in global setting and more than 50 years in Nepali context, adoption rate of distance learning is not that much encouraging. Before 20 or 30 years, it could have been the complexity in relaying message through diverse broadcasting channels or financial aspect associated with distance learning. But that is not the case anymore. However, the situation has not progressed.

Research finding from 160 responses were categorized into two groups as participant with prior experience $(43.3 \%)$ and participant without prior experience $(56.7 \%)$. Higher proportion of participants preferred laptop as electronic device to attend distance classes with tablet being the lowest preferred device. From technology perspective, participant mutually agreed about large number of populations not being able to afford laptop to attend class though they agree with fact, people are somehow comfortable with available technologies. Meanwhile, participants agreed about existing internet facilities being not up to the mark to provide smooth operation during class hours further causing dis-interest at classes and disturbances during class-hours. Regardless of their experiences, research participant agreed on the interaction level, clarity on information and degree of attentiveness at moderate level during distance classes. Whereas the degree of distraction being the higher level. From the use of teaching-learning material perspective, majority $(87.3 \%)$ of the research participant preferred presentation slides followed up with video slides (67.5\%) and narrative/explanation being the lowest (34.4\%). From the applicability perspective, research participant agreed on the applicability of distance classes for theory-based courses as high probability and technical course as low probability. Though research participant perceived the applicability of practical course being low, finding is statistically different across students from groups (with prior experience and without prior experience). From academic level perspective, research participants mutually agreed on its applicability at all level, under SEE and high school being moderate, low and moderate. Though research participant perceived the applicability of distance classes being high at bachelor and above level, their responses is difference across student groups. From the course modality perspective, majority (89.7\%) preferred blended modality with an application of both virtual mode and traditional classroom modality.

Overall, this research brought out some of the aspects associated with distance learning such as lack of interaction between student-student and student-teacher; inconsistent internet facilities; socio-economic conditions of students creating the situation of being unable to afford required technologies for distance learning; lack of curriculum focused on distance learning; occupied mind-set with traditional education setting; limited capacity among available human resources to adopt distance learning; and no opportunities of group exercises, demonstration and practical related activities on distance learning set-up. Similarly, distance learning does have its own share of opportunities in the form of revenue generating opportunity; availability of unlimited learning materials in digital mode; familiarity of individuals with advanced technologies; opportunity to get certified degree from any part of the globe; and save of time, energy and finance.

With the findings and further analysis, this research brought the underlying opportunities and challenges associated with distance learning as reference for policymakers and education related stakeholders. This findings and learnings can be further capitalized for further wider level consultations to appropriately discuss and plan for application of distance learning at Nepali academic setting. 
Reference

Abede. T. D \& Deneke. T. D. (2008). Causes of Students' Limited Participation in EFL Classroom: Ethiopian Public Universities in Focus. International Journal of Educational Research and Technology

Abdullah. Y. M. et. al. (2012). Student's participation in classroom: What motivates them to speak up. Procedia-Social and Behavioral Sciences.

Chantrea. B. et. al. (2018). Working and Studying at the Same Time. University of Cambodia

Dodd. T. (Nov. 21, 2016). Education exports hit $\$ 21$ billion a year as Chinese student numbers surge. The Australian Finance Review

Durey. E. (October 28, 2015). At universities, more students are working full-time. The Atlantic

Garrison. et. al. (2011). Article Review- Social Presence within the Community of Inquiry Framework. International Review of Research in Open and Distance Learning

Kharel. S. (December 2018). Information and Communication Technology for the Rural Development in Nepal. Tribhuwan University Journal. Vol. 32. No. 2

McIssac. S. M. \& Gunawardena. N. C. (August 3, 2001). The Handbook of Research for Educational Communication and Technology. The Association for Educational Communications and Technology (AECT)

Moore. M. (1997). Theory of Transactional Distance. Theoretical principles of distance education. Routledge

NTA (February 12, 2020). MIS Report. Nepal Telecommunication Authority

Pant. A. (November 2014). Distance Learning: History, Problems and Solution. Krishi Sanskriti Publications. Advances in Computer Science and Information Technology (ACSIT). ISSN: 23939907, Volume 1, Number 2. pg. 65-70

Pangeni. K. S. (2016). Open and Distance Learning: Cultural Practices in Nepal. European Journal of Open, Distance and e-learning. Vol. 19. No. 2. https://www.doi.org/101515/eurodl-2016-0006

Purdue (2018). Community of Inquiry Framework. Purdue University

Sapkota. S. (September, 2012). Teacher Education through Distance Mode: The Nepalese Experience. Centre for Research in Education and Educational Technology. The Open University, UK

Tavukcu. T. et. al. (2011). General overview on distance education concept. Procedia Social and Behavioral Sciences

UNESCO (2002). Open and Distance Learning: Trends, Policy and Strategy Considerations. Division of Higher Education, UNESCO. 